\title{
Anaesthesia for a Child with Down syndrome UndergoingCleft Palate Repair and Review of Anaesthesia Management of Other Associated Congenital Syndromes
}

\author{
*Amarjeet D.Patil ${ }^{1}$, Amrita Nandi ${ }^{2}$, Vishwas Sathe ${ }^{3}$, Rakesh Singh ${ }^{4}$, Kanha \\ Agrawal $^{5}$,Sunita A.Patil ${ }^{6}$, R.L.Gogna ${ }^{7}$ \\ ${ }^{1}$ Assistant Professor, ${ }^{2}$ Resident,${ }^{3}$ Assistant Professor, ${ }^{4,5}$ Resident,${ }^{6}$ Senior Resident, ${ }^{7}$ Professor \& HOD \\ Department of Anaesthesiology,MGM Medical College \& Hospital, Kamothe, Navi Mumbai - 410209.
}

\begin{abstract}
Cleft lip/palate are the most common craniofacial anomalies in children, with an incidence of 1:800 live births. Cleft palate alone occurs in 1:2000 live births ${ }^{1}$.It occurs due to the failure of fusion or break in fusion of nasal and maxillary processes with the palatine shelves, which form during $8^{\text {th }}$ week of the embryonic period. About 150 syndromes may be associated with cleft deformities. The most well-known are the Pierre Robin's, TreacherCollins and Goldenhaar syndrome. Congenital heart disease (CHD) occurs in 5-10\% of these patients ${ }^{l}$.Surgical repair of cleft lip is usually done at 1-3 months of age for cosmetic purpose and cleft palate at 6 months to 1 year of age to promote facial growth and the speech. The successful outcome following cleft repair depends on the age of the patient, associated morbidities, anaesthetic expertise and post-operative care ${ }^{1}$. Infants with facial deformities are usually associated with abnormal dentition/hearing defect, recurrent ear/upper respiratory tract infection (URTI), pulmonary aspiration and poor nutrition. Until recently criteria for cleft repair in infants was 10 pounds of weight, 10 weeks of age and haemoglobin of $10 \mathrm{gm} \%^{2}$. Recent concepts of early repair in neonates are based on improvements in parent-infant bonding, feeding, growth and speech development ${ }^{2}$.

Anaesthesia for cleft surgery in infant and children carries a higher risk with general anaesthesia and airway complications due to associated respiratory problems. Review of literature mentions higher incidence of perioperative respiratory complications when associated with the common cold symptoms in children for cleft repairs ${ }^{3,4}$. Morbidity during general anaesthesia is associated with the difficult airway, endotracheal (ET) tube compression/disconnection and post-operative airway obstruction ${ }^{1,4}$.

Down syndrome or Trisomy 21 is the most common chromosomal abnormality, and similar to KFS it also results in anatomical changes of the airways, such as: cleft lip and palate, narrow nasopharynx, and relatively large and protuberating tongue. The larynx and the cricoid ring tend to be small predisposing to acquired subglottic stenosis. Patients might have atlantoaxial subluxation, making neck extension risky ${ }^{l}$.

Here we are presenting a $5 \mathrm{yr}$ old male child with weight of $12 \mathrm{~kg}$ for cleft palate repair with Down syndrome done under general anaesthesia.He was having complete cleft palate was seen with a bifid uvula. The cardiovascular,respiratory and per abdominal examinations had no positive findings.However,CNS examination showed hypotonia in all four limbs with power 2/5 in upper limbs and lower limbs.
\end{abstract}

Keywordsdown syndrome, cleft palate, general anaesthesia

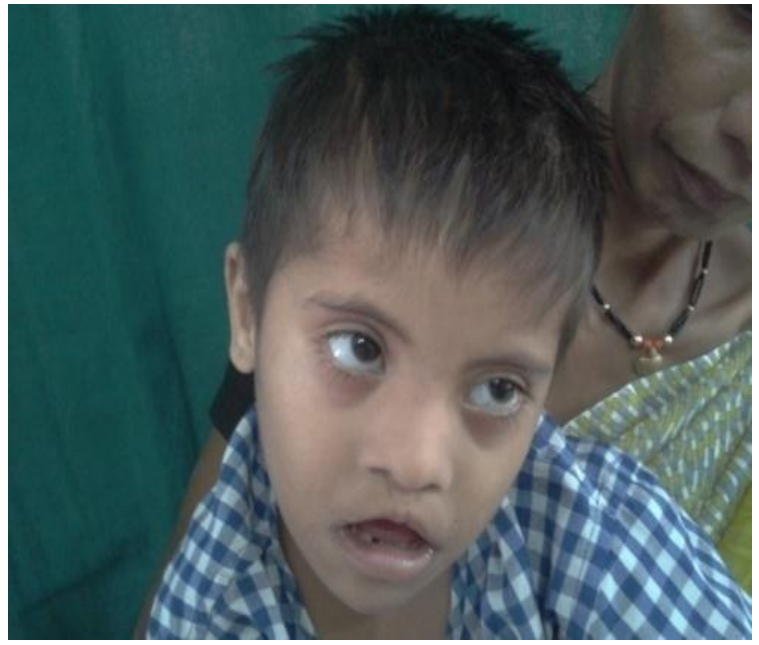

Image 1-Patient 


\section{Introduction}

Cleft lip/palate are the most common craniofacial anomalies in children, with an incidence of 1:800 live births. Cleft palate alone occurs in 1:2000 live births ${ }^{1}$.It occurs due to the failure of fusion or break in fusion of nasal and maxillary processes with the palatine shelves, which form during $8^{\text {th }}$ week of the embryonic period. About 150 syndromes may be associated with cleft deformities. The most well-known are the Pierre Robin's, Treacher Collins and Goldenhar syndrome. Congenital heart disease (CHD) occurs in 5-10\% of these patients ${ }^{1}$. Down's syndrome is the commonest chromosomal abnormality and is named after John Langdon Down, whodescribed the syndrome in $1866^{6}$. Down's syndrome is also referred to as Trisomy 21 due to the presence ofan extra copy of chromosome number 21. It has an incidence of 1.5 per 1000 live births ${ }^{7,8}$. Maternal age is arisk factor for Down's syndrome and the risk increases with maternal age. A 20 year-old mother has a risk ofabout 1 in 2000 while a 35 year-old mother has an estimated risk of 1 in 400 . The risk increases to 1 in 40 at $45 y e a r s$ of age ${ }^{9}$. This syndrome affects many organ systems, and there is impaired global development. Many ofthese problems have significance for the anaesthetist.

\section{Case Report}

A $5 \mathrm{yr}$ old male child with weight of $12 \mathrm{~kg}$ presented to our hospital in the pediatric department with complaints of difficulty in swallowing since birth and speech defect. On taking history it was revealed that the patient was delivered at home at term and cried immediately after birth. Since birth the child was unable to take feeds orally, as whatever was fed to him regurgitated through his nose. He was taken to a local physician who diagnosed him with cleft palate (Figure 2) and adviced surgery at 5 years of age. Child also had history of recurrent upper respiratory tract infections. His gross and fine motor, language and social milestones were all delayed . On general physical examination showed his weight and height was below the third percentile. The child had a flat occiput with parietal and frontal bossing. He had an upward slant of eyes with epicanthal folds. He also had a flat nasal bridge. Oral examination showed an open mouth (fish shaped) with a large tongue. A complete cleft palate was seen with a bifid uvula. The cardiovascular,respiratory and per abdominal examinations had no positive findings.However,CNS examination showed hypotonia in all four limbs with power $2 / 5$ in upper limbs and lower limbs.

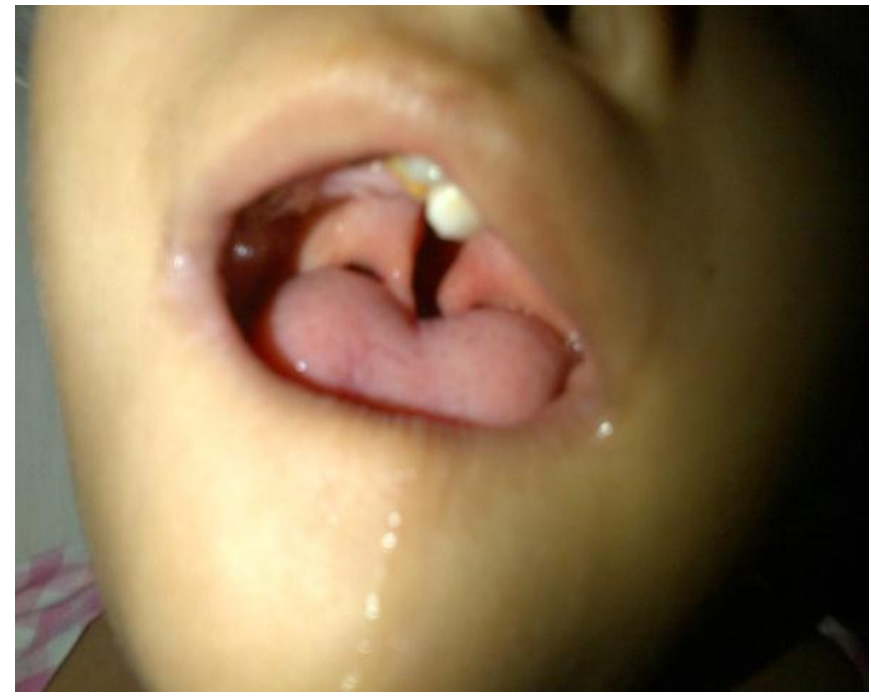

Image 2-Cleft Palate

With the given history and the positive examination findings a diagnosis of down syndrome with cleft palate was made. Routine blood tests were ordered during pre anestheticcheck up which were normal. Special tests included 2D echo to rule out associated congenital cardiac condition, thyroid profile test to rule out hypothyroidism both of which had a normal report. X ray neck was ordered with special emphasis on the atlanto axial joint to rule out atlanto axial ligament laxity which is commonly seen in patients with downs syndrome. Xray revealed no abnormal findings. The child was accepted under ASA II and posted for surgery.

Pre-operative fasting was observed for $4 \mathrm{~h}$ for milk, $6 \mathrm{~h}$ for solid food and $2 \mathrm{~h}$ for clear fluid. Baseline vital parameters like heart rate (HR), non-invasive blood pressure (NIBP), (ECG), pulse oximetry $\left(\mathrm{SpO}_{2}\right)$ were noted inside the O.T. Pre cordial stethoscope fixed. All the anaestheticequipments and drugs were checked. The ET tubes (Ring, Adair and Elwyn (RAE) south polar tube for cleft lip, Oxford/Armoured for cleft palate) and LMAs of appropriate sizes were kept ready.

Premedication given wasinj.glycopyrrolate $0.04 \mathrm{mg}$, midazolam $0.12 \mathrm{mg}$ and inj. Fentanyl $25 \mu \mathrm{g}$ IV.Diclofenac suppository $(25 \mathrm{mg})$ was put per rectally as pre emptive analgesia. Patient was induced with inj. Thiopentone $60 \mathrm{mg}$ and succinylcholine $25 \mathrm{mg}$ IV. After 30 secs of bag and mask ventilation with oxygen patient was 
intubated with 4.5 no. uncuffedSouthpoleRAE tube. Tube was fixed after checking bilateral air entry. Throat packing was done. Maintainance of anaetheisia was carried out with manual ventilation with bag and mask with oxygen, nitrous oxide, sevoflurane and atracurium. Inj.dexamethasone $2.5 \mathrm{mg}$ was given to reduce post operative intraoral oedema. Patient received $300 \mathrm{ml}$ of isolytePand $100 \mathrm{ml}$ of colloid(HAES-3\%). Patient had an urine output of $85 \mathrm{ml}$ and total $100 \mathrm{ml}$ of blood loss. The intraoperative period was uneventful.
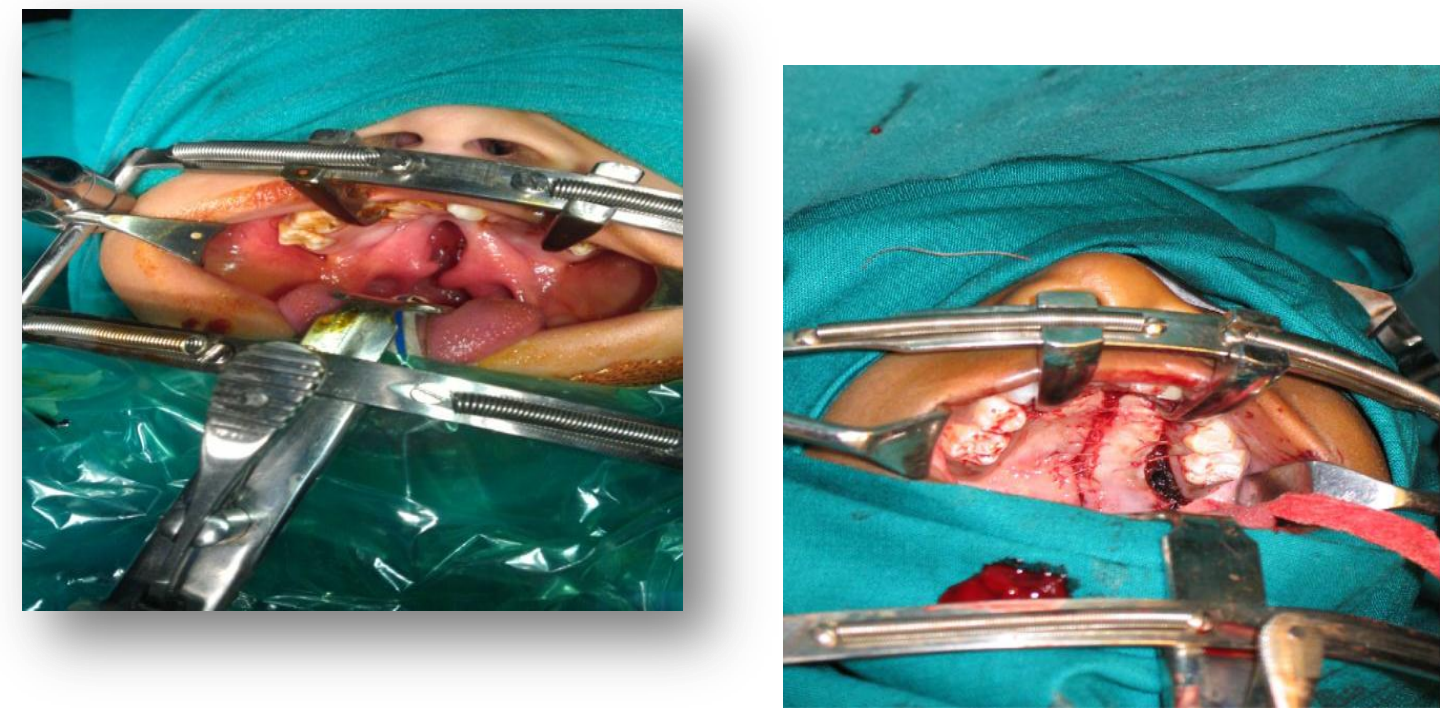

Image 3-IntraoperativeImage 4-Postoperative

At the end of surgery, patient was reversed with inj.neostigmine $0.6 \mathrm{mg}$ and inj.glycopyrrolate $0.08 \mathrm{mg}$. Throat pack was removed and thorough ET and oral suctioning was done. Patient was extubated when the child was fully awake and his reflexes were intact. Child was put in left lateral postion after extubation and was supplemented with oxygen at 4 liters/minutes with Hudson mask. After 30minutes of observation the patient was shifted to PICU for post operative care. Patient had an uneventful post operative period and was shifted out of PICU to ward after 24 hours. The child was discharged after 7 days of hospital stay.

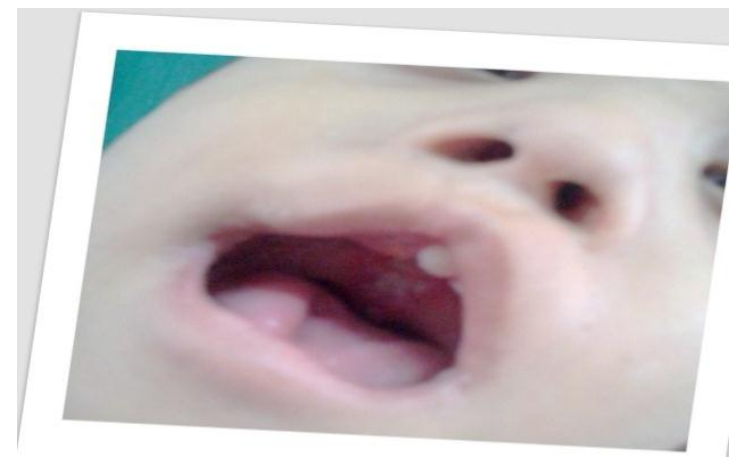

Image 5-Post operative image of the patient

\section{Discussion}

Twenty percent of all children with a cleft will havesome other congenital abnormality, most of whichare not part of a recognizable syndrome. Ifclassified by the organ system involved, malformationsof the upper and lower limbs and vertebraeare the commonest group, being present in $5 \%$ of allcases ${ }^{10}$.Usually these are minor abnormalities(accessory digits or club foot deformities) and do

not affect anaesthetic management. Abnormalitiesof the cardiovascular system are the secondcommonest group, affecting $4 \%$ of all cleft children,(a 16-fold increase in prevalence over thegeneral population), with ventricular septal defectsbeing the commonest single abnormalityseen.

More than three hundred syndromes havenow been described involving the combination of a cleft with multiple other congenital abnormalities.The syndromes of the head and neck, includingthose involving abnormalities in branchial archdevelopment, are particularly important. Theyare commonly difficult to intubate, and thereforewill be individually described.Treacher Collins syndrome is a bilateral symmetricalabnormality of 
the first and second branchialarches, resulting in hypoplasia of the maxilla,zygoma and mandible. Intubationis difficult due to the small jaw and retropositionedtongue.Pierre Robin sequence (PRS) is not an individualsyndrome, but a group of conditions involvingabnormal development of the mandible (a derivativeof the first branchial arch) in utero.

It consists of:

(a) micrognathia (a small symmetrical retro-positionedjaw)

(b) glossoptosis (tongue displaced high and posteriorlydue to the small jaw, causing airwayobstruction)

(c) mid-line U shaped cleft of the palate.

At birth, the facial features of PRS are often quitemarked, and severe airway obstruction and feedingdifficulties common. Soft nasopharyngeal airwaysheld in place by acrylic splints will often maintain aclear airway in hospital, allowing time for spontaneousimprovement to occur as the infant grows.Many infants have PRS in isolation, with no otherabnormalities. Here, the small mandible is felt tobe due to external restriction to growth in utero,and significant catch up growth is possible duringearly childhood, if airway and feeding problems aretreated. In other infants the small jaw is due tointrinsic abnormality of the mandible, as part of asyndrome, and catch up growth post-delivery willnot be possible. These infants have other abnormalitiessuggestive of an underlying syndrome.

Thecommonest are:

(a) Stickler's syndrome.

(b) Velocardiofacial syndrome.

(c) Foetal alcohol syndrome.

Stickler's syndrome is a connective tissue dysplasiaof autosomal dominant inheritance with variablepenetrance. Ophthalmic problems including retinaldetachments are common and thus all children withPRS should undergo ophthalmic review.Velocardiofacial syndrome (VCF) is a geneticcondition characterized by structural and palatalabnormalities, cardiac defects, unique facial characteristicsand mild learning difficulties. Although VCF syndrome is the most common cleftrelatedsyndrome, associated with least $8 \%$ of allcleft palates, it was first described as recently as 1978 by Dr. Robert Shprintzen of the MontifioreMedical Centre, Bronx, New York. It is the secondcommonest syndromic cause of congenital heartdisease after Down's syndrome. The resultingphenotype is very wide. The underlying chromosomalabnormality is a deletion in position 11 of thelong arm of chromosome 22 (22q11 deletion),picked up by chromosomal fluorescence in situhybridization (FISH test).

Hemifacialmicrosomia (Goldenhaar's syndrome) isa relatively common birth defect involving poordevelopment of the first and second branchialarches on one side. This leadsto facial asymmetry with a small mandible, maxillaand zygoma on one side of the face. Most cases aresporadic.

Children with Down's syndrome are generally gentle, cheerful and outgoing, but they may have a tendencytowards hyperactivity, and will have limited understanding compared to normal children of their age. It is bestto conduct thepre-anaesthetic visit when the parent or carer is with the child. The anaesthetist should try toexplain (to the child) what is going to happen in a language appropriate to the child; the presence of the parentor carer will be greatly reassuring for the child. It is important that the parent has a clear explanation of theanaesthetic procedure and what to expect.

Play therapists may also have a role to ensure smooth induction ofanaesthesia.Structural heart disease in children with Down's syndrome is common and there should be a high index ofsuspicion. Symptoms suggestive of congenital heart disease include failure to thrive, breathlessness and fatigueon exertion, or unexplained 'funny turns'. Important signs include central cyanosis, finger clubbing, respiratorydistress, signs of cardiomegaly with displaced cardiac apex, hepatomegaly or the presence of a heart murmur,possibly with associated 'thrill' (palpable murmur).

The characteristics of pathological murmurs are as follows:

- All murmurs associated with cardiac signs or symptoms

- All pansystolic and diastolic murmurs

- Late systolic murmurs

- Loud murmurs, those associated with a thrill, or continuous murmurs

A detailed cardiovascular examination, ECG, and ideally a cardiology opinion and echocardiography should beobtained in all children with Down's syndrome before proceeding with surgery ${ }^{19}$.A thorough examination of the respiratory system and airway is necessary to rule out a difficult airway orintubation. History of snoring during sleep associated with daytime lethargy and somnolence, behaviouralchanges, poor concentration and inattention at school may suggest the presence of severe obstructive sleepapnoea (OSA). Children with severe OSA are not suitable for day case surgery.Atlanto-axial instability is seen in $15 \%$ of children with Down's syndrome. History of neck pain, limited neckmobility or head tilt, change in gait pattern, clumsiness, abnormal neurological reflexes, abnormal sensation orpresence of bladder and bowel dysfunction suggest the possibility 
of neck problems. Atlanto-axial instability isdiagnosed by identifying an increase in the distance between the posterior border of the arch of the atlas and theanterior border of the odontoid peg on lateral flexion and extension radiographs of the cervical spine (atlantodentalinterval, ADI) [see fig 1,2]. In children over eight years old, the ADI should be $3 \mathrm{~mm}$ or less while inyounger children the ADI should be $4 \mathrm{~mm}$ or less (some consider up to $5 \mathrm{~mm}$ as normal) ${ }^{20}$.

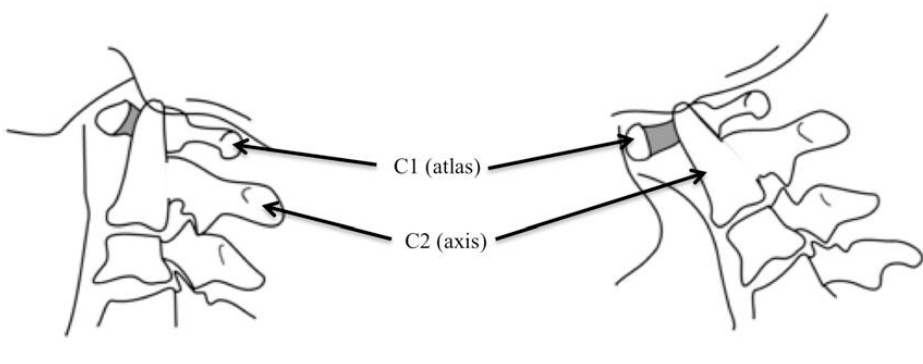

Figure 1 - Flexion

Figure 2 - Extension

Figures $1 \&$ 2. Line diagram of the atlas $(\mathrm{C} 1)$ and axis $(\mathrm{C} 2)$ vertebrae showing increased atlantodental interval (shaded area) in extension. The odontoid peg (dens) of $\mathrm{C} 2$ projects from the superiorsurface of the body of $\mathrm{C} 2$ and may move to cause spinal cord compression ${ }^{21}$

Currently, there is no consensus in the literature to suggest whether every patient with Down's syndrome shouldbe screened radiologically prior to an anaesthetic/surgical procedure. However, it is recommended that if thereare signs and symptoms suggestive of cervical cord compression or a difficult laryngoscopy is anticipated or ifthe surgery requires that the neck is placed in a non-neutral position for a long time intraoperatively, thencervical spine radiography should be performed before an elective case ${ }^{22}$. If cervical spine radiography is notdone in an asymptomatic Down's syndrome patient, then the goal should be to keep the head and neck in aneutral position.

In a study looking into the safety of neck rotation for ear surgery, Todd et al have concludedthat patients with Down's syndrome who are neurologically intact with normal neck radiographs do not appearto be at high risk with neck rotation up to 60 degrees $^{23}$. However, there has been a case report where the ADIhas been normal prior to surgery but post operatively the ADI increased, requiring upper cervical fusion at a later date ${ }^{22}$.

Despite cleft repair being a relatively commonoperation worldwide, there are no prospectivestudies comparing different anaesthetic techniques.Many papers describe the use of specificdrugs, usually reflecting the agents availablelocally, and use mortality as a measure of anaestheticsuccess. Despite this lack of informationthere is general agreement on the principles (if notthe detail) of anaesthetic management of theinfant presenting for primary cleft repair.

\section{(a) Pre-operative assessment}

Repair of a cleft involves sharing the airway withthe surgeon. To provide the best possible access tothe operative site the infant will need to beintubated with a south facing tube, and ventilationcontrolled in view of the age of the patient andlikely duration of the surgery. Two key questionsdominate the pre-operative assessment of any childpresenting for surgery:

(a) Is another congenital abnormality or a syndromepresent?

(b) Is intubation likely to be difficult?

In view of the high incidence of congenital heartdisease, all infants require thorough examination ofthe cardiovascular system. The presence of anymurmur warrants an echocardiogram to assess thestructure of the heart. The multi-specialist natureof cleft care in the United Kingdom means thatmany infants with underlying syndromes will havebeen picked up prior to surgery and the extent ofassociated abnormalities identified.The methods of airway assessment used in adultsto predict the degree of difficulty with intubationare not useful and cannot readily be applied ininfants. No specific thyromental distance has beenvalidated as being a cut off for a difficult intubation, and clearly infants cannot cooperate withMallampati scoring.

The majority of non-syndromicinfants are easy to intubate and, even if the larynxis difficult to view, are usually straightforward toventilate. Gunawardana has prospectively reporteda series of $800 \mathrm{cleft}$ patients managed over a 10 -year period ${ }^{11}$. Difficult laryngoscopy (Cormack andLehane Grade III or IV once cricoid pressure hadbeen applied) was present in $7 \%$ of patients, andwas associated with retrognathia, age less than 6months and bilateral cleft with prominent premaxilla. None of these patients was difficultto ventilate. The incidence of failed intubation was $1 \%$. However, two points are important whenconsidering this series from Sri Lanka. Firstly, nochild was known to have a syndrome, and secondlya straight laryngoscope blade was not tried in anypatient. 
In the developed world, more childrenwith syndromes survive and present for cleftsurgery. The physiological changes in any syndromemust be fully understood before an anaesthetic isgiven.Despite the lack of a definitive test fordifficult intubation, children should be examinedpre-operatively for signs of retrognathia.The history must also include questions topick up any breathing problems or feedingdifficulties since birth, how they were managedand whether they have resolved. A diagnosisof PRS, Treacher Collins syndrome or hemifacialmicrosomia must be assumed to predict adifficult intubation until proved otherwise.Standard starvation policies are followed andthis author does not routinely use an atropinepremedication.

\section{(b) Anaesthetic management}

Either an intravenous or gaseous induction ofanaesthesia may be undertaken. In the age group3 months to 1 year, when venous access is difficult,gentle gaseous induction, using a cupped hand andT piece, with either halothane or sevoflorane inoxygen, usually allows smooth loss of consciousnessand separation from the parent. If intubation isexpected to be straightforward, and once it isconfirmed that ventilation may be easily assisted,administration of a non-depolarizing muscle relaxantwill facilitate the process. An adequate view ofthe larynx is usually easily achieved with gentlecricoid pressure and a choice of curved and straightlaryngoscope blades. Apaediatric gum elasticbougie is the most useful aid to intubation. Caremust be taken not to bruise the lip or palate to berepaired. The tendency of the laryngoscope to fallinto a wide cleft may be overcome in twoways - packing the lip cleft with a small gauze rollor using the laryngoscope to approach from the sideof the mouth rather than in the midline.

Where intubation is expected to be difficult thesame initial approach as above may be taken. Thechoice then is either to keep the infant spontaneouslybreathing and view the larynx under deepinhalational anaesthesia, or to confirm that ventilationmay be easily assisted by hand, administer amuscle relaxant and then view the larynx. In anychild with severely abnormal facial anatomy,maintaining spontaneous ventilation is the safestapproach. If the larynx remains difficult or impossibleto view, a range of approaches is possible.Inserting a laryngeal mask airway (LMA) provides apatent airway, a route to deliver anaestheticagents, and a conduit through which a fibre-opticlaryngoscope may be inserted to view the larynx. Aguide wire may then be passed into the trachea.The fibre-optic laryngoscope and LMA are thenremoved, and the endotracheal tube passed overthe wire into the trachea ${ }^{12}$. The guide wire needs tobe stiff enough or it will be displaced as theendotracheal tube is pushed over.

Alternatively,with spontaneous ventilation, an endotracheal tubemay be cut to length, placed as a nasopharyngealairway, and anaesthesia maintained via one nostrilwhile intubation is performed with the fibreopticlaryngoscope via the other. Multiple other methodsof management have been described. Once theairway has been secured, ventilation is thencontrolled to maintain normocapnia, thus avoidingvasodilatation and excess blood loss from theoperative site.

For a lip repair, intra- and postoperative painrelief may be achieved with local anaestheticblockade of the infraorbital nerves. The site ofthe infraorbital foramen varies with age, andconcerns about the close proximity of the eye inthe neonate led Bosenberg to propose inserting thelocal anaesthetic through the $\operatorname{skin}^{13}$. This authorprefers a more classical "dental approach", insertingthe needle between the lip and gum intothe sulcus, with a finger placed anteriorly toconfirm the extent of needle advancement aslocal anaesthetic is administered. This block,in association with regular oral analgesia, provideseffective pain relief. A loading dose of paracetamol $20 \mathrm{mg} / \mathrm{kg}$ rectally is recommended ininfants and should be administered as early aspossible. It takes $2 \mathrm{~h}$ for a rectal dose ofparacetamol to reach peak serum concentration,and a further hour for it maximally to passacross into the brain (effect site) ${ }^{24}$.

Clinicalexperience suggests that the addition of anon-steroidal anti-inflammatory drug (NSAID), prescribedregularly, improves analgesia with noincreased incidence of postoperative haemorrhagerequiring a return to theatre.For a CP repair, a Dingman retractor or Dottmouth guard are used to keep the mouth open andhold the tongue and endotracheal tube away fromthe surgical field (Image $3 \& 4$ ). As the gag is beingopened it is important to check that the endotrachealtube is not being crushed or occluded.Armoured endotracheal tubes are not recommendedas they are readily displaced. A smallgauze throat pack is placed by the surgeon toreduce aspiration of blood. Following induction,intravenous antibiotic prophylaxis, particularlyagainst Staphylococcus, is important.

The nerve supply to the hard and soft palateis from the greater and lesser palatine nervespassing through the sphenopalatine ganglion.There is no simple, long-lasting block thatprovides effective postoperative analgesiaafter CP repair without risking interference withswallowing. Although surgical infiltration is undertakenwith short acting local anaesthetic andvasoconstrictor, it rarely blocks the profoundautonomic response caused by the operation,nor provides effective post-operative pain relief.Short acting opioids (fentanyl $3 \mathrm{mcg} / \mathrm{kg}$ for a $1 \mathrm{hprocedure)}$ in association with an inhalationalagent effectively block a major part ofthe autonomic response. This means that intraoperativeblood pressure is well controlled,providing a relatively bloodless surgical field andreducing the need for blood transfusion. Remifentanilby infusion in combination 
with an inhalationagent has been shown to provide intraoperativehaemodynamic stability in infants undergoing cleftrepair, but no specific advantage over other shortacting opioids has been demonstrated ${ }^{15}$. With allshort acting opioids, intravenous morphine isrequired in the initial postoperative period. Regularadministration of paracetamol and NSAIDs is alsovaluable.

When a Cleft palate has been repaired an infant's airway issmaller than pre-operatively. Obstruction to theupper airway may occur at the time of extubation.

Causes include:-

1. Critical reduction in size of a previous tenuousairway

2. Excessive sedation from opioids, so that infantfails to adequately hold the tongue forward.

3. Laryngeal oedema due to a large endotrachealtube, resulting in stridor.

Ideally, extubation should only take place once theinfant is fully awake and has full control of itsairway reflexes. Few prospective series exist, but a5\% rate of immediate upper airway obstruction onextubation has been reported, and occurs particularlyin children with an associated syndrome(especially PRS) ${ }^{16}$. Very gentle placement of anasopharyngeal airway is frequently effective,providing a clear airway, a route to undertakesuction and, if inserted gently, not prejudicing therepair. It is usually needed for less than $24 \mathrm{~h}$. Onoccasions re-intubation and ventilation is required.Episodes of late upper airway obstruction, up to24-48h post operatively, where re-intubation andventilation was necessary, are also well described. Causes include swelling of the tongue due toischaemia from excessive retraction by the gag.All at risk infants should therefore be observedclosely in the initial postoperative period for thedevelopment of upper airway obstruction.

\section{Conclusion}

Down's syndrome is a common congenital anomaly which is associated with multi-system problems that needthorough assessment pre-operatively. Of particular importance is the assessment of airway, cervical spine (forsigns and symptoms of atlanto-axial instability), cardiovascular and respiratory system. Children may presentwith varying degrees of learning disabilities. Anaesthesia should be carefully planned and the risks discussedwith the parents/carers. Peri-operative complications include airway obstruction, difficult intubation,bradycardia, post-extubation stridor, bronchospasm and rarely, neurological problems due to atlantoaxialsubluxation. With adequate pre-operative preparation and good intra-operative care, children with Down'ssyndrome can be anaesthetised safely. Post-operatively, the children should be closely observed in the recoveryroom and adequate analgesia and anti-emetics should be prescribed to ensure that the child is pain free andcomfortable.

\section{References}

[1]. Law RC, de Klerk C. Anesthesia for cleft lip and palate surgery. UpdatAnesth. 2002;14:27-30.

[2]. Sandberg DJ, Magee WP, Jr, Denk MJ. Neonatal cleft lip and cleft palate repair. AORN J.2002;75:490-8.

[3]. Desalu I, Adeyemo W, Akintimoye M, Adepoju A. Airway and respiratory complications in children undergoing cleft lip and palate repair. Ghana Med J. 2010;44:16-20.

[4]. Takemura H, Yasumoto K, Toi T, Hosoyamada A. Correlation of cleft type with incidence of perioperative respiratory complications in infants with cleft lip and palate. Paediatr Anaesth.2002;12:585-8.

[5]. Nargozian C - The airway in patients with craniofacial abnormalities. PaediatrAnaesth, 2004; 14:53-59

[6]. Carvalho B. Down's syndrome p212-214. In: Oxford Handbook of Anaesthesia. Ed: Allman KG, Wilson IHOxford University Press 2003

[7]. Roizen MF. Anesthetic Implications of Concurrent Diseases.p974 In: Anesthesia Ed: Miller RD. ChurchillLivingstone 2000. 5th edition;.

[8]. Kobel M, Creighton RE and Steward DJ. Anaesthetic considerations in Down's syndrome: Experience with100 patients and a review of the literature. Canadian Anaesthesiology Society Journal 1982: 29; 593-599.

[9]. Diseases common to the pediatric patient. p602-603 In: Anesthesia and co-existing disease. Ed: StoeltingRK,Dierdorf SF 3rd edition. Churchill Livingstone.

[10]. Milerad J, Larson O, Hagberg C, Ideberg M. Associated malformations in infants with cleft lip and palate: aprospective, populationbased study. Pediatrics1997;100(2Pt1):180-6.

[11]. Gunawardana RH. Difficult laryngoscopy in cleft lip andpalate surgery. Br J Anaesth 1996;76(6):757-9.

[12]. Dubreuil M, Ecoffey C. Laryngeal mask guided tracheal intubation in paediatricanaesthesia. PaediatrAnaesth1992;2:344.

[13]. Bosenberg AT, Kimble FW. Infraorbital nerve block inneonates for cleft lip repair: anatomical study and clinicalapplication. Br J Anaesth 1995;74(5):506-8.

[14]. Anderson B. Acetaminophen analgesia in infants. AnesthAnalg2001;93(6):1626-7.

[15]. Roulleau P, Gall O, Desjeux L, Dagher C, Murat I.Remifentanil infusion for cleft palate surgery in younginfants. PaediatrAnaesth 2003;13(8):701-7.

[16]. Antony AK, Sloan GM. Airway obstruction following palatoplasty:analysis of 247 consecutive operations. Cleft PalateCraniofac J 2002;39(2):145-8

[17]. Bell CN, Macintyre DR, Ross JW, Pigott RW, Weller RM.Pharyngoplasty: a hazard for nasotracheal intubation. Br JOralMaxillofacSurg 1986;24(3):212-6.

[18]. Liao YF, Noordhoff MS, Huang CS. Comparison of obstructivesleep apnea syndrome in children with cleft palate followingFurlowpalatoplasty or pharyngeal flap for velopharyngealinsufficiency. Cleft Palate Craniofac J 2004;41(2):152-6.

[19]. ATOTW 93'Recognising cardiac Disease in Children' (Elizabeth Storey, 26/05/2008).

[20]. Mik G, Gholve PA, Scher DM et al. Down syndrome: orthopaedic issues. Current Opinion in Pediatrics2008: 20; 30-36. 
[21]. Dr. Krishnan Melarkode - Great Ormond Street Hospital NHSTrust, UK. “Anaesthesia for children with down'ssyndrome". Anaesthesia tutorial of the week 139,22nd June 2009.

[22]. Hata T, Todd M. Cervical spine considerations when anesthetizing patients with Down syndrome.Anesthesiology 2005; 102: 680-5.

[23]. Todd NW, Holt PJ, Allen AT. Safety of neck rotation for ear surgery in children with Down syndrome.Laryngoscope 2000; 110: 1442-5.

[24]. Anderson B. Acetaminophen analgesia in infants. AnesthAnalg 2001;93(6):1626-7. 